\title{
Receiver function images of the central Chugoku region in the Japanese islands using Hi-net data
}

\author{
D. S. Ramesh ${ }^{1}$, H. Kawakatsu ${ }^{2}$, S. Watada ${ }^{2}$, and X. Yuan ${ }^{3}$ \\ ${ }^{1}$ National Geophysical Research Institute, P.B. 724, Hyderabad-500007, India \\ ${ }^{2}$ Earthquake Research Institute, University of Tokyo, 1-1-1 Yayoi, Bunkyo-ku, Tokyo 113-0032, Japan \\ ${ }^{3}$ GeoForschungsZentrum, Telegrafenberg, 14473 Potsdam, Germany
}

(Received November 1, 2004; Revised March 16, 2005; Accepted March 16, 2005)

\begin{abstract}
Crustal configuration of the central Chugoku region with disposition of the Philippine Sea Plate (PHS) in this area are investigated through the receiver function approach using short-period Hi-net data. Images of the upper mantle discontinuities are also obtained. Restituted short-period receiver functions bring out discernible variations in average composition of the crust and its thickness in the study region. The $V p / V s$ values in the study area are generally high, reaching values in excess of 1.85 at a few places. The central part of the study region showing the highest $V p / V s$ values is coincidentally a subregion of least seismicity, possibly bestowed with special subsurface structure. Migrated receiver function images, both $P s$ and $P p s$ images, unambiguously trace the NW subducting PHS taking a steeper plunge in the northwest part of the Chugoku region reaching depths of $70 \mathrm{~km}$ from its low dip disposition in the southeast. An excellent correlation of the subducting PHS with the hypocenters is also seen. We demonstrate that short-period data after restitution and application of appropriate low pass filters can indeed detect presence of the global $410-\mathrm{km}$ and $660-\mathrm{km}$ discontinuities and map their disposition reasonably well. Our migrated receiver functions image the deflections in the $410-\mathrm{km}$ and $660-\mathrm{km}$ discontinuities in an anti-correlated fashion on expected lines of Clapeyron slope predictions induced by subduction of the Pacific plate (PAC) beneath Japanese islands, though PAC itself is feebly traced but shows good correlation with slab seismicity.
\end{abstract}

Key words: Central Chugoku, Hi-Net, Japan, Migration, Receiver Functions, Short period data.

\section{Introduction}

The Japanese islands are located in an acknowledged region of tectonic complexity encompassed by various convergent plate boundaries. Until recently most of the $P$-to- $S$ migrated receiver function images beneath the Japanese islands focus on the structure of the mantle using broadband data from various networks. These bring out some details of the subducting Pacific plate (PAC) and the Philippines sea plate (PHS) that include their geometry; slab-mantle interaction; the underlying mantle stratification; nature disposition of the mantle transition zone etc. (Li et al., 2000; Tada, 2001; Yamauchi et al., 2003; Tonegawa et al., 2004). Receiver function (RF) images that focus on the configuration of the subducting PHS in southwest Japan trace it rather well beneath Shikoku and Seto Inland Sea regions (Shiomi et al., 2004) but its detection further north into Chugoku region still remains ambiguous and weak. Reasons for an impeded or non-traceable PHS beneath Chugoku region remain unclear till knowledge of the sub-structure in this region vis-a-vis disposition of the PHS becomes available. Therefore, study of Chugoku region assumes importance in light of the above. Little attention is however paid to the composition-thickness of the crust and possible manifes-

Copy right(c) The Society of Geomagnetism and Earth, Planetary and Space Sciences (SGEPSS); The Seismological Society of Japan; The Volcanological Society of Japan; The Geodetic Society of Japan; The Japanese Society for Planetary Sciences; TERRAPUB. tations of mantle related processes in the overlying crust. Existing RF studies trace the Moho inland to be a weakly mapped feature due to its small $P$-to- $S$ conversion efficiency except in northeast Japan where Moho is relatively sharp and continuous (Tada, 2001; Shiomi et al., 2004). Variability in quality and clarity of the $P$ and $S$ multiple phases of the primary $P$-to- $S$ (Moho) conversion is also observed. Consequently, estimates of Moho depth $(H)$ and Poisson's ratio $(\sigma)$ in an independent fashion using the $P$ to- $S$ conversions from the Moho and its $P$ multiple together with its $S$ counterpart would be less accurate.

We selected 37 stations of the Hi-net, restricted to an area $133^{\circ} \mathrm{E} / 34^{\circ} \mathrm{N} / 135^{\circ} \mathrm{E} / 35.5^{\circ} \mathrm{N}$ (Fig. 1) in the central part of Chugoku region for few reasons. Firstly, this region seems to be less studied in terms of the underlying structure. The only earlier attempts, to our knowledge, using instrument corrected short-period RFs (Shiomi et al., 2004) and both short-period and broadband data (Tada, 2001, Yamauchi et al., 2003) reveal a transparent crust in this region without even clear $P$-to- $S$ signals from the Moho and Conrad, suggesting that the proposed study region may have small $P$-to$S$ conversion efficiency at these boundaries. Consequently, detection of the PHS and its disposition in the region remains obscure. Secondly, this small region is interestingly bestowed with least seismicity in an otherwise seismically prolific Japan accompanied by sparse volcanism. Therefore, it should be illuminating to understand the composi- 


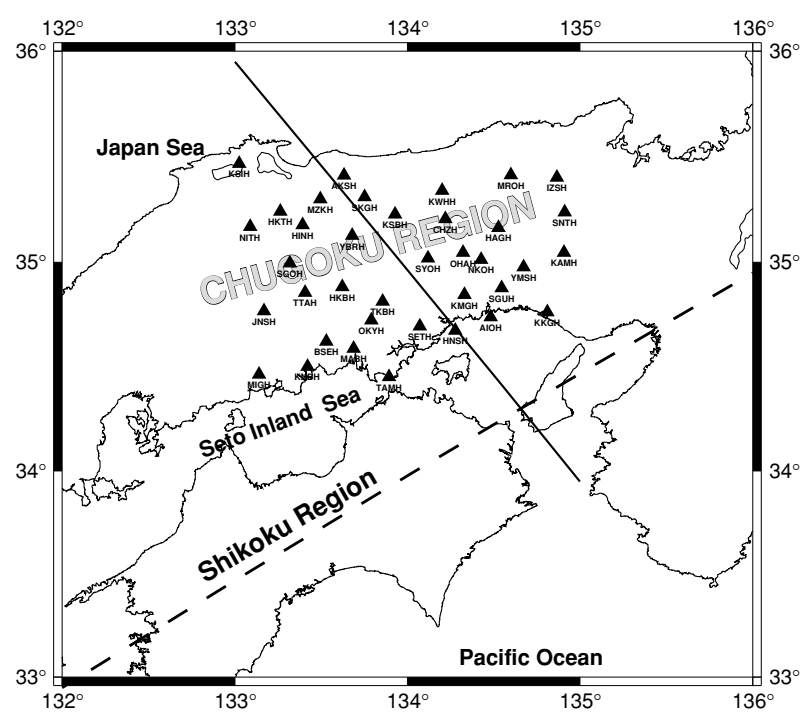

Fig. 1. Station location map (37 stations) covering the study region (Chugoku) in the Japanese Islands. Stations belong to the Japanese 'Hi-net' network equipped with ML4-3-D sensors with a natural period of $1 \mathrm{~s}$ installed in boreholes. The solid line indicates the location of cross-section (NW-SE) presented in Fig. 8 to trace the PHS. The dashed line shows the location of cross-section (SW-NE) along which Fig. 9 is constructed to map the PAC.

tion the crust in such a special region that imparts both: apparent stability in terms of low seismicity and low $P$-to- $S$ conversion efficiency. Thirdly, this exercise, though preliminary in nature, is also intended to study the power and limitations of short period (data) RFs and strategise effective ways and means to make better use of the large Hi-net data that are accruing to study the underlying structure.

The details of the $P$-to- $S$ migrated broadband RF images of the subducting PAC and the PHS can be summarized as under. To the south, the PHS shows decipherable variability both in its direction (W-NW to near N-S) and steepness of subduction (dip angle ranges between a high $35^{\circ}$ to a shallow $10^{\circ}$ ) reaching variable depths (as high as $90 \mathrm{~km}$ ) beneath the tectonically diverse sub-regions of the Japanese islands in the southwest, central and northeast. The subducting slab shows both aseismic and seismic character under these terrains at varying depths. The RF migrated images beneath the Japanese islands distinctly trace the westward rapidly descending PAC till about $200 \mathrm{~km}$ and document the deflections in the $410-\mathrm{km}$ and $660-\mathrm{km}$ discontinuities in an anticorrelated fashion on expected lines of Clapeyron slope predictions for subduction scenario. The PAC penetrates the 410-km elevating it locally by $30 \mathrm{~km}$ without large deviations elsewhere but varying in sharpness as evident from its frequency dependence which remains to be resolved as yet (Tada, 2001; Tonegawa et al., 2004; Yamauchi et al., 2003).

Close to the study area, to the south, till the Seto Inland Sea the PHS is traced to depths of about 50-60 km showing good correlation with hypocenters in the region. Its traceability further, into northern Chugoku seems obscure and impeded. In this context, it should be rewarding to investigate the cause. It should be interesting to examine the disposition of the rapidly descending PAC in the study region using short-period records. The depth contours of PAC
(Zhao et al., 1994) suggest that it reaches depths in excess of $400 \mathrm{~km}$ beneath the study region. An important question is whether the restituted short-period data is 'broadband' enough to pick signals from the subducting plate and is its contrast with the surrounding mantle at depths robust enough to be mapped by the shortperiod data. We attempt to present short-period $P$-to- $S$ migrated sections discussing these aspects.

\section{Data and Methods of Analysis}

The RF method, a relatively modern tool to model the crustal structure beneath a station using teleseismic $P$ waves, decomposes the wave field into its $P, S V$ and $S H$ components through rotation of the recorded threecomponent seismograms. This is accomplished using either the event azimuth (back-azimuth) information (Z, R, T system) and/or angle of incidence (L, Q, T system). Further, to isolate the $P$-to- $S$ converted phases within the $P$ coda, deconvolution is performed. Deconvolving the $P$ from the $S V$ component does this. Such a procedure also accounts for source related and common path effects. The resulting RFs now have information of the near-receiver structure thus enabling us to model the crust-mantle structure beneath a seismic station. In our study, we essentially follow the methods described by Vinnik (1977) and elaborated in Kind et al. (1995) to construct and treat RFs. In order to make recordings of different slowness comparable, we apply a moveout correction (Yuan et al., 1997) that reduces the RFs to a fixed slowness of $6.4 \mathrm{~s} /{ }^{\circ}$, corresponding to an epicentral distance of $67^{\circ}$.

Teleseismic earthquake data recorded at 37 threecomponent stations (Fig. 1) that belong to the Japanese Hinet network (Obara, 2002) equipped with ML4-3-D sensors with a natural period of $1 \mathrm{~s}$ installed in boreholes were used. Their sensitivity is around $200 \mathrm{~V} / \mathrm{m} / \mathrm{s}$. Details of instrumentation about this network can be obtained from Obara (2002). A total of 818 RFs from 33 good quality stations generated by about 25 earthquakes well distributed in azimuth with high signal-to-noise ratio $(\mathrm{SNR} \geq 3)$ were finally selected for analysis. In our study, the $P$-to- $S$ converted signals ( $P s$ phase) from any interface (e.g. Moho) with adequate velocity contrast, and their multiply reflected and converted waves between the surface and the interface, known as multiples (designated Pps, $P s s$ ) are used to determine the depth to the interface (e.g. Moho) and constrain the average $V p / V s$ (related to $\sigma$ ) of the intervening region.

Data from short period records are restituted and bandpass filtered. The range of band-pass period best suited for the data varies from a minimum of 2 or $3 \mathrm{~s}$ up to a maximum of 15 or $20 \mathrm{~s}$. The resultant filtered RFs have come out with sharper $P s$ and multiple arrivals. A $P s$ moveout corrected slowness stack section for station $\mathrm{KAMH}$, for both, the original RFs (Fig. 2(a)) and their restituted, filtered version (Fig. 2(b)) is presented. Data and plotting options remain same for both. The stacks binned in $0.2 \mathrm{~s} /{ }^{\circ}$ slowness interval are presented using reasonably good data at this generally noisy station. Note that in the original data stacks, the crustal $P$ and $S$ multiples designated Pps and Pss respectively, are not obvious to recognise in the expected time window of their arrivals in view of competing arrivals in 

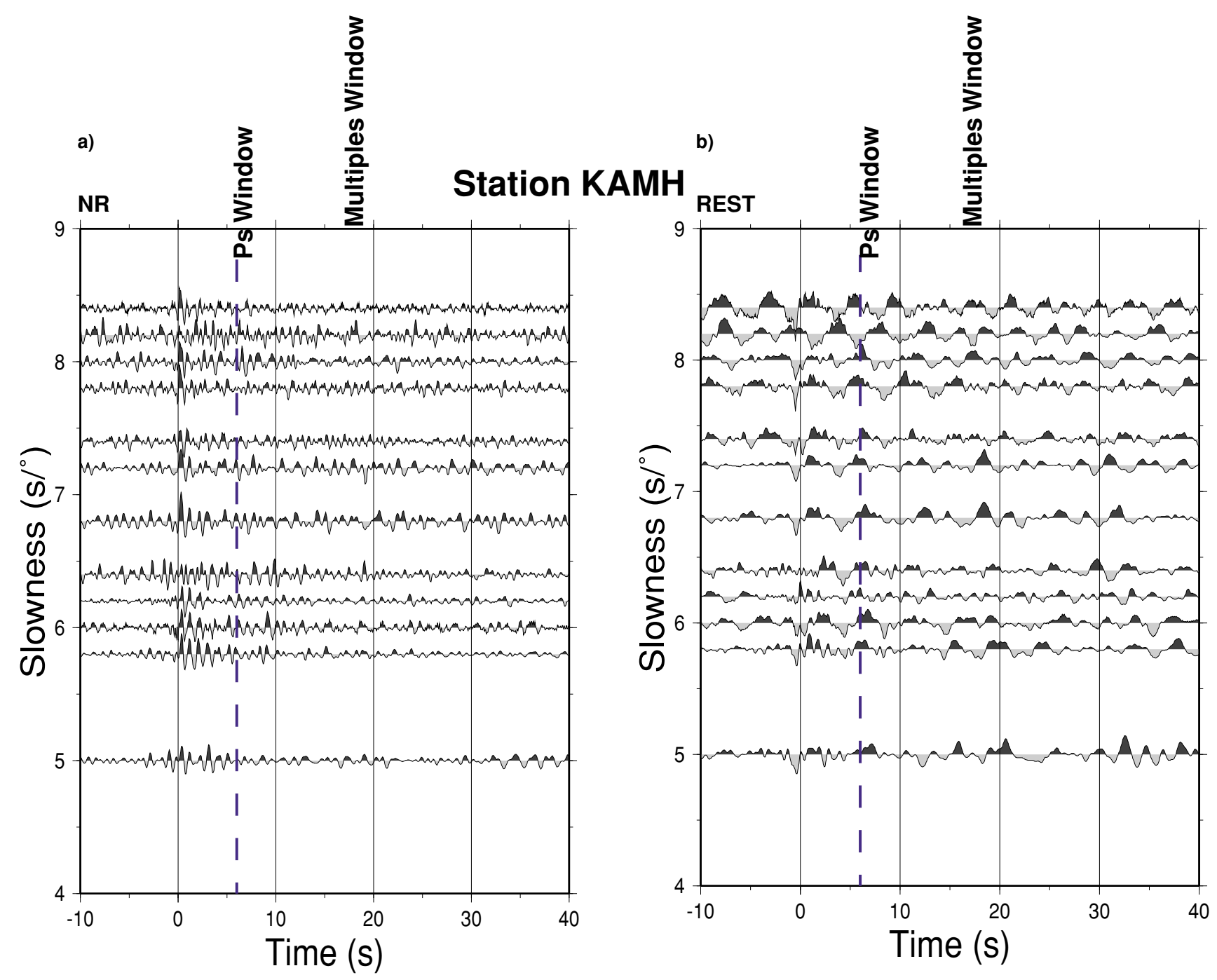

Fig. 2. Move-out corrected (for $P s$ phase) RF slowness stack sections (reference slowness of $6.4 \mathrm{~s} /{ }^{\circ}$, corresponding to an epicentral distance of $67^{\circ}$ ) at station KAMH ("slowness" here refers to that of incoming $P-S$ converted phase at Moho, $P s$, and is a function of epicentral distance). Stack-sections with label prefix 'NR' (a) from original recordings while that with 'Rest' (b) is after restitution. The stacks binned in $0.2 \mathrm{~s} /{ }^{\circ}$ slowness interval are presented using reasonably good data at this generally noisy station. Note that in original data the crustal multiples designated Pps and $P s s$ are not obvious to recognise in the expected time window of their arrivals in view of competing arrivals in the vicinity of the actual multiple phase.

the vicinity of the actual multiple phases. In contrast, the $P s$ and its multiples appear as relatively clear and distinct phases after restitution and filtering (Fig. 2(b)). Such data can now be used to determine $H-V p / V s$ values by methods like Zhu and Kanamori (2000) to obtain better-constrained crustal parameters. In this method, $H$ and $V p / V s$ are estimated by performing a grid search over a wide range of $H$ and $V p / V s$ values, to find the optimal values that maximize the summation of amplitudes of the Ps, Pps and Pss phases. The grid search scheme was employed over a depth range of 10-50 km and $V p / V s$ range of 1.5-2.5 adopting standard weights of 7, 2, and 1 for the Ps, Pps and Pss phases respectively to recover the crustal parameters from the RFs at each station. In this study, we assume a uniform average $V p$ value of $6.3 \mathrm{~km} / \mathrm{s}$ for the whole crust beneath all the stations.

To enable appreciate the quality of data used in determination of $H-V p / V s$ values; we present slowness stack (binned in $0.2 \mathrm{~s} /{ }^{\circ}$ slowness interval) sections at a few individual stations (Figs. 3(a)-(f)). These Ps moveout cor- rected restituted sections for stations are selected to sample various segments of the study area and also to represent acceptable quality of the crustal multiples used in further analysis. The sections presented reflect the quality of their observations. The Ps, Pps and Pss phases are marked in the sum traces. Note that the multiples have an opposite move-out compared to the Ps phase as seen earlier in Fig. 2. This behaviour of multiples is another diagnostic to recognise them. Each station stack section is low-pass filtered applying $2 \mathrm{~s}$ period filters for purposes of presentation. Stations KSIH, TAMH, AKSH and SKGH yield unusable data for any further analysis. Further, to assess data quality at all stations, the sum traces of individual stations covering both the $P s$ arrival window and those of multiples are presented in Figs. 4(a)-(c). In view of importance of multiples in $H-V p / V s$ determination by the grid search method, these parameters are not determined for stations JNSH, NITH, $\mathrm{KMGH}$ and $\mathrm{KSBH}$ either due to very weak registration of multiples and/or Ps phase. 

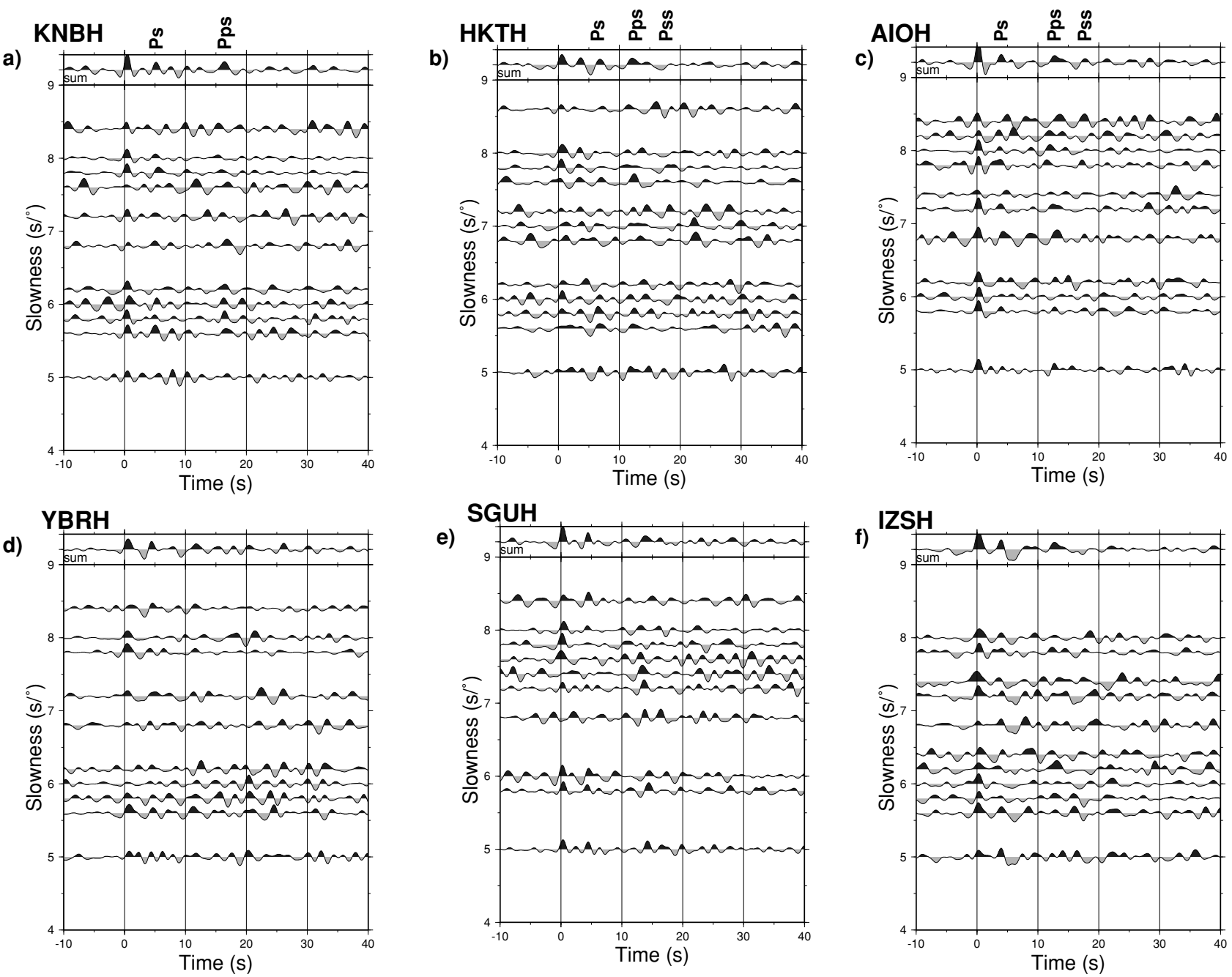

Fig. 3. Slowness stack sections at a few sample individual stations. These restituted sections for stations are selected to sample few parts of the study area and also to represent acceptable quality of the crustal multiples used in further analysis. The sections presented reflect the quality of their observations and their choice is deliberate in that aspect. The Ps and Pps, Pss phases are marked in the sum traces. Note that the multiples have an opposite moveout compared to the $P s$ phase. This behaviour of multiples is another diagnostic to recognise their presence. Each station stack section is low-pass filtered applying 1.5 to 3 second period filters of various orders ( 1 to 3 ) for purposes of presentation.

\section{Results and Discussion}

\subsection{Crustal thickness and Poisson's ratio}

Recognising that the study region could generally be complex in nature owing to its unique tectonic setting, variation in crustal thickness and $V p / V s$ are expected to be large. The standard bootstrap technique is used to estimate the uncertainty in the $H$ and $V p / V s$ parameters. In this approach data sets are constituted by randomly picking samples from the original data pool, and subjected to the grid search analysis for determination of $H-V p / V s$ parameters. This operation is performed 200 times for each station. The resultant average model parameters $H$ and $V p / V s$ along with their scatter are presented in Table 1. It can be seen that the spread in the estimates of the parameters shows reasonable correlation with the quality of registration of the $P s$ and multiple phases. Stations JNSH, NITH are omitted from analysis (see Fig. 4) either due to poor phases ( $P s$ or Pps or both) or complicated nature of the traces (multiple arrivals close to $P s$ or $P p s$ times). Station KSIH is also omitted from the initial analysis because of its noisy character. Estimates at HKBH could be off due to not so energetic Pps phase (see Table 1). Stations TAMH, SKGH and AKSH are omitted from initial analysis for same reasons as KSIH, while stations KMGH and KSBH are found not fit for grid-search analysis due to reasons cited for JNSH and NITH. In general, stations of better quality (A, B in Table 1) yield tighter estimates compared to those with lower quality. The results of $H-V p / V s$ estimate from a few sample short period stations are presented in Figs. 5(a)-(f). Note that the quality of data used is clearly reflected in the nature of closures obtained in the $H-V p / V s$ domain. The crustal parameters, $H$ and $V p / V s$ values thus determined at each station are presented at their respective locations in Figs. 6(a) and 6(b) respectively.

The Chugoku region is generally characterised by $H$ values centered on $35 \mathrm{~km}$ with $V p / V s$ values in excess of the global average of 1.79 (Zandt and Ammon, 1995). Interestingly, good quality stations underlain by a thick crust yield $V p / V s$ values close to 1.78 , indicating their predominantly felsic character. A northward thinning of the crust (to about $30 \mathrm{~km}$ ) associated with high (1.85 and above) $\mathrm{Vp} / \mathrm{Vs}$ values can be observed (Figs. 6(a) and (b)). Except in the SW 
a)

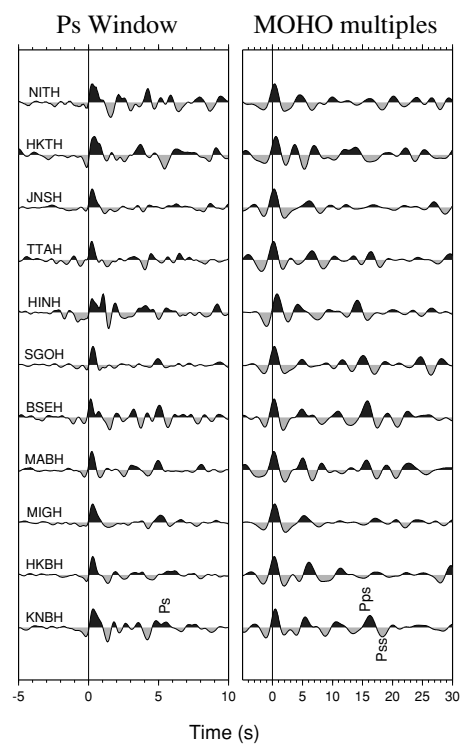

b)

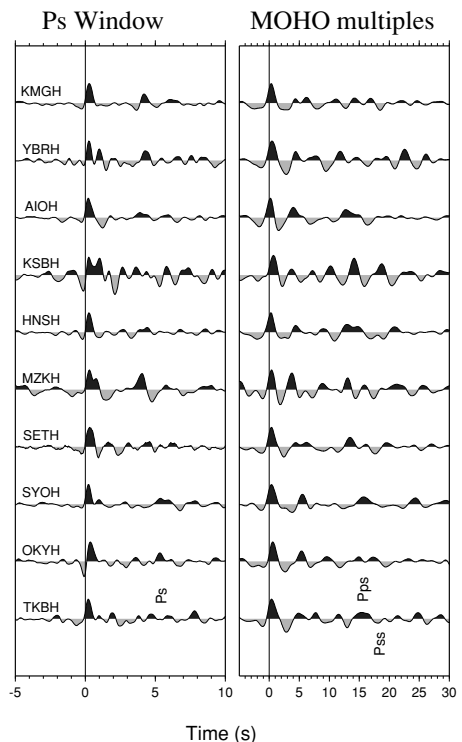

c)

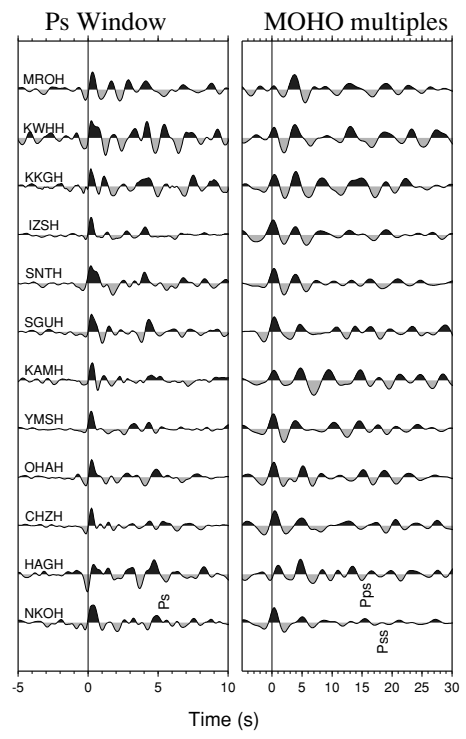

Fig. 4. Moho Ps conversions and its multiples designated Pps and Pss on RF sum traces at individual stations (four-letter codes) of the Hi-net. The stations are displayed in increasing order of Moho depth (crustal thickness) from top to bottom. The figure in the left-hand panel covers the $P s$ time window while that in the right-hand panel with longer time window covers the range of arrival of multiples Pps and Pss. The data in left-hand panel are restituted with no low pass filtering while the sum traces in right-hand panel are low-pass filtered with $3 \mathrm{~s}$ corner period.

a)
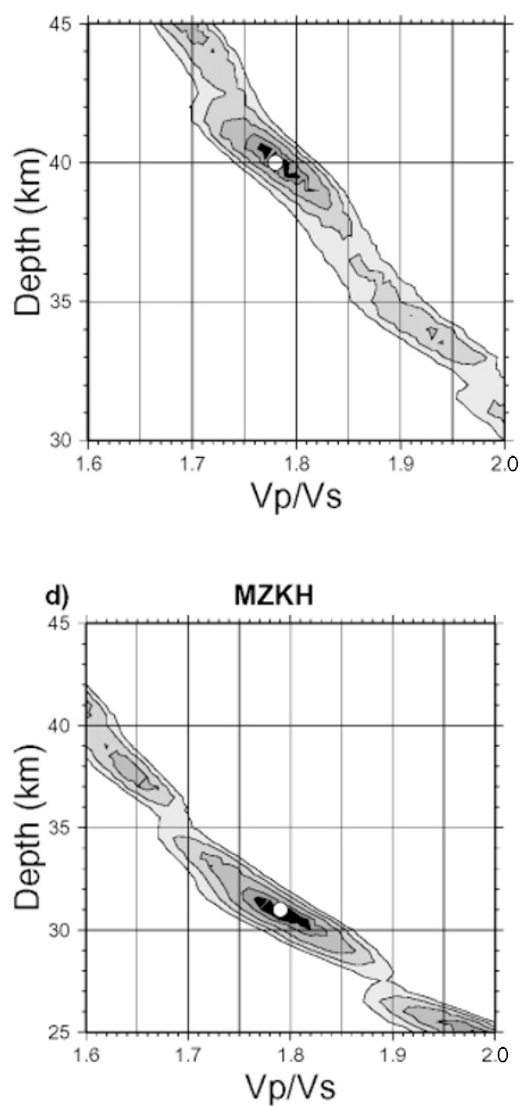

b)
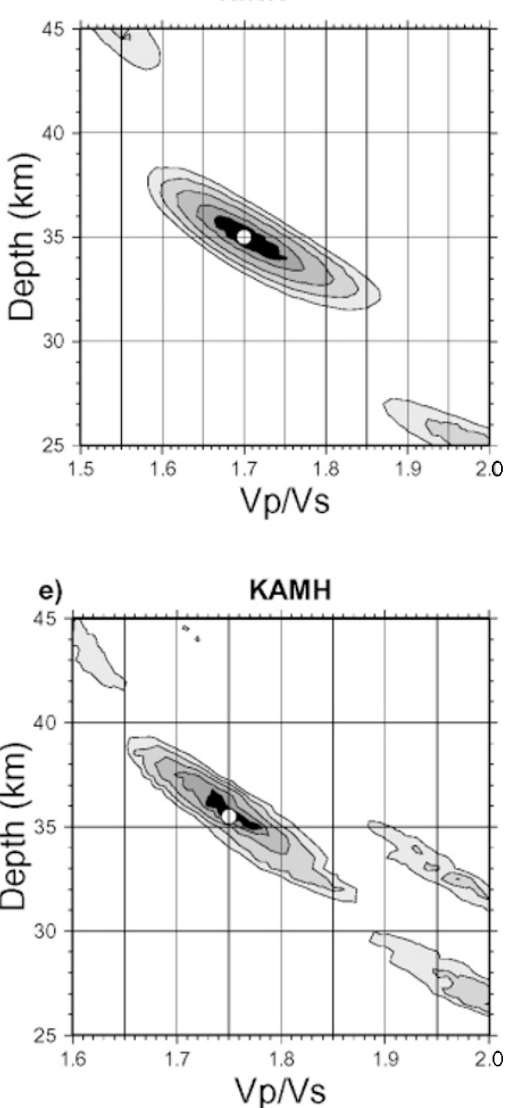

c)
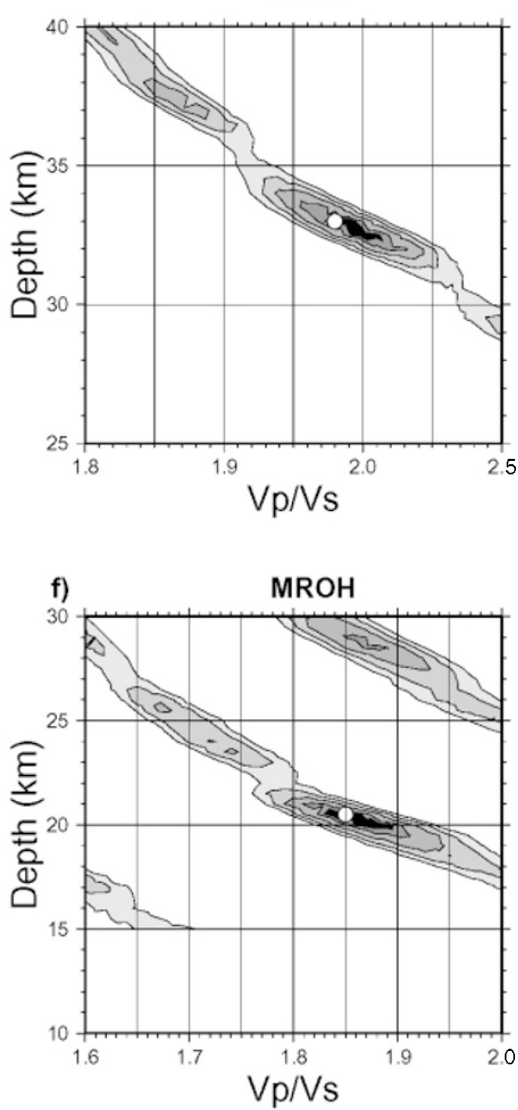

Fig. 5. Average crustal $V p / V s$ values versus $H$ at a few sample stations. The grid-search using the Zhu and Kanamori (2000) approach was employed over a depth range $10-50 \mathrm{~km}$ and $V p / V s$ range $1.5-2.5$ adopting the standard weights of 7, 2, 1 for the Ps, Pps and Pss phases to recover the crustal parameters from the constructed RFs. 
Table 1. Station codes with locations, crustal thickness $(H)$ and $V p / V s$.

\begin{tabular}{|c|c|c|c|c|c|c|}
\hline Stn. code & Long $\left({ }^{\circ} \mathrm{E}\right)$ & Lat $\left({ }^{\circ} \mathrm{N}\right)$ & $H(\mathrm{~km})$ & $V p / V s$ & No. of RFs & Quality \\
\hline MIGH & 133.1401 & 34.5150 & $40.0 \pm 2.2$ & $1.78 \pm 0.05$ & 25 & A-B \\
\hline $\mathrm{KNBH}$ & 133.4205 & 34.5534 & $37.6 \pm 4.4$ & $1.77 \pm 0.07$ & 24 & A \\
\hline MABH & 133.6888 & 34.6397 & $36.7 \pm 3.6$ & $1.78 \pm 0.10$ & 29 & B \\
\hline BSEH & 133.5309 & 34.6724 & $36.8 \pm 3.4$ & $1.81 \pm 0.04$ & 25 & A \\
\hline HNSH & 134.2771 & 34.7251 & $29.0 \pm 4.5$ & $1.87 \pm 0.10$ & 28 & B \\
\hline SETH & 134.0728 & 34.7468 & $31.7 \pm 6.2$ & $1.81 \pm 0.11$ & 18 & A-B \\
\hline OKYH & 133.7917 & 34.7751 & $35.0 \pm 4.1$ & $1.97 \pm 0.08$ & 29 & $\mathrm{~B}$ \\
\hline $\mathrm{AIOH}$ & 134.4819 & 34.7903 & $29.3 \pm 6.2$ & $1.90 \pm 0.15$ & 28 & B \\
\hline $\mathrm{KKGH}$ & 134.8106 & 34.8132 & $34.2 \pm 5.0$ & $1.89 \pm 0.16$ & 15 & A-B \\
\hline JNSH & 133.1701 & 34.8193 & - & - & 27 & $\mathrm{D}$ \\
\hline TKBH & 133.8554 & 34.8652 & $37.8 \pm 9.0$ & $1.98 \pm 0.18$ & 25 & B-C \\
\hline KMGH & 134.3311 & 34.8963 & - & - & 29 & D \\
\hline TTAH & 133.4081 & 34.9071 & $33.7 \pm 4.0$ & $1.90 \pm 0.15$ & 25 & B \\
\hline SGUH & 134.5450 & 34.9281 & $32.5 \pm 2.8$ & $1.81 \pm 0.08$ & 25 & B \\
\hline $\mathrm{HKBH}$ & 133.6232 & 34.9331 & $26.8 \pm 12.0$ & $1.85 \pm 0.14$ & 29 & C-D \\
\hline YMSH & 134.6736 & 35.0278 & $35.2 \pm 5.1$ & $1.78 \pm 0.10$ & 25 & B \\
\hline SGOH & 133.3196 & 35.0461 & $34.0 \pm 5.4$ & $1.89 \pm 0.15$ & 25 & B \\
\hline $\mathrm{NKOH}$ & 134.4261 & 35.0639 & $35.2 \pm 8.1$ & $1.85 \pm 0.17$ & 27 & $\mathrm{C}$ \\
\hline $\mathrm{SYOH}$ & 134.1189 & 35.0700 & $34.6 \pm 4.3$ & $1.95 \pm 0.11$ & 24 & A-B \\
\hline OHАН & 134.3217 & 35.0967 & $34.2 \pm 5.0$ & $1.84 \pm 0.14$ & 27 & $\mathrm{~B}$ \\
\hline KAMH & 134.9064 & 35.0978 & $35.2 \pm 5.4$ & $1.78 \pm 0.14$ & 28 & B \\
\hline YBRH & 133.6792 & 35.1777 & $29.3 \pm 6.1$ & $1.95 \pm 0.11$ & 21 & B \\
\hline HAGH & 134.5264 & 35.2161 & $35.5 \pm 6.7$ & $1.82 \pm 0.15$ & 29 & B-C \\
\hline NITH & 133.0882 & 35.2203 & - & - & 29 & $\mathrm{D}$ \\
\hline HINH & 133.3937 & 35.2281 & $35.3 \pm 2.0$ & $1.74 \pm 0.08$ & 25 & $\mathrm{~A}$ \\
\hline $\mathrm{CHZH}$ & 134.2200 & 35.2572 & $33.5 \pm 7.4$ & $1.88 \pm 0.16$ & 25 & $\mathrm{~B}-\mathrm{C}$ \\
\hline $\mathrm{KSBH}$ & 133.9290 & 35.2794 & - & - & 27 & $\mathrm{D}$ \\
\hline SNTH & 134.9098 & 35.2894 & $28.3 \pm 5.6$ & $1.90 \pm 0.18$ & 28 & C-D \\
\hline HKTH & 133.2630 & 35.2931 & $22.5 \pm 7.0$ & $1.88 \pm 0.20$ & 24 & $\mathrm{~B}$ \\
\hline MZKH & 133.4944 & 35.3522 & $29.4 \pm 3.3$ & $1.80 \pm 0.10$ & 25 & A-B \\
\hline KWHH & 134.2015 & 35.3914 & $33.3 \pm 7.4$ & $1.89 \pm 0.16$ & 18 & B-C \\
\hline IZSH & 134.8649 & 35.4543 & $30.0 \pm 4.1$ & $1.84 \pm 0.14$ & 25 & A-B \\
\hline $\mathrm{MROH}$ & 134.5980 & 35.4665 & $22.0 \pm 4.6$ & $1.85 \pm 0.06$ & 28 & B-C \\
\hline
\end{tabular}

Quality:

A- Stations with distinct, energetic $P s$ and $P p s$ registrations

B- Distinguishable $P s, P$ s phases that are clear but broader with competing arrivals of small amplitudes in their arrival window vicinity

C- Either $P s$ and/or Pps poorly registered

D- Complicated RFs with weak or no $P s$ and $P$ ps phases. Discarded from analysis

quadrant where crustal thickness estimates reach $40 \mathrm{~km}$, stations to the south show a thinner crust with the usual high $V p / V s$ values. Therefore, in the study region variations in $H$ can be between $22 \mathrm{~km}$ to $40 \mathrm{~km}$. Importantly, the study region has $V p / V s$ values in excess of 1.80 reaching close to 2.0 suggesting dominance of mafic to ultra-mafic composition in the crust with thickness smaller than $35 \mathrm{~km}$. In terms of $V p / V s$ the central part of the study region with very high (in excess of 1.85) $V p / V s$ values that reach about 2.0, emerges as the most anomalous region.

To understand the above distribution of Poisson's ratio (related to $V p / V s$ ) in the general context of seismicity of the study region, we selected earthquakes restricted to the study area $\left(133^{\circ} \mathrm{E} / 34^{\circ} \mathrm{N} / 135^{\circ} \mathrm{E} / 35.5^{\circ} \mathrm{N}\right)$ in the depth range $0-30 \mathrm{~km}$ with magnitudes in excess of 3.0 for the pe- riod 1950-2002 from the Japanese Meteorological Agency (JMA) database and plotted their locations (Fig. 7) on our $V p / V s$ map. The most glaring feature is association of least seismicity with the central part of the study area characterised by the highest $V p / V s$ (clearly in excess of 1.89) values and restriction of earthquakes to its periphery. Most of the seismicity in the entire region is generally in close proximity to stations that show high (yellow, 1.79-1.89) $\mathrm{Vp} / \mathrm{Vs}$ values with a few exceptions though (Fig. 7). This general lack of seismicity in this central part could have a potential causal link to the phenomenon of earthquake occurrence or its absence, a topic of interest to many in Japan. A possible explanation for the decreased prolificacy of seismicity could be that the regional stresses do not transmit into this anomalous part, with the peripheral faults associated with 

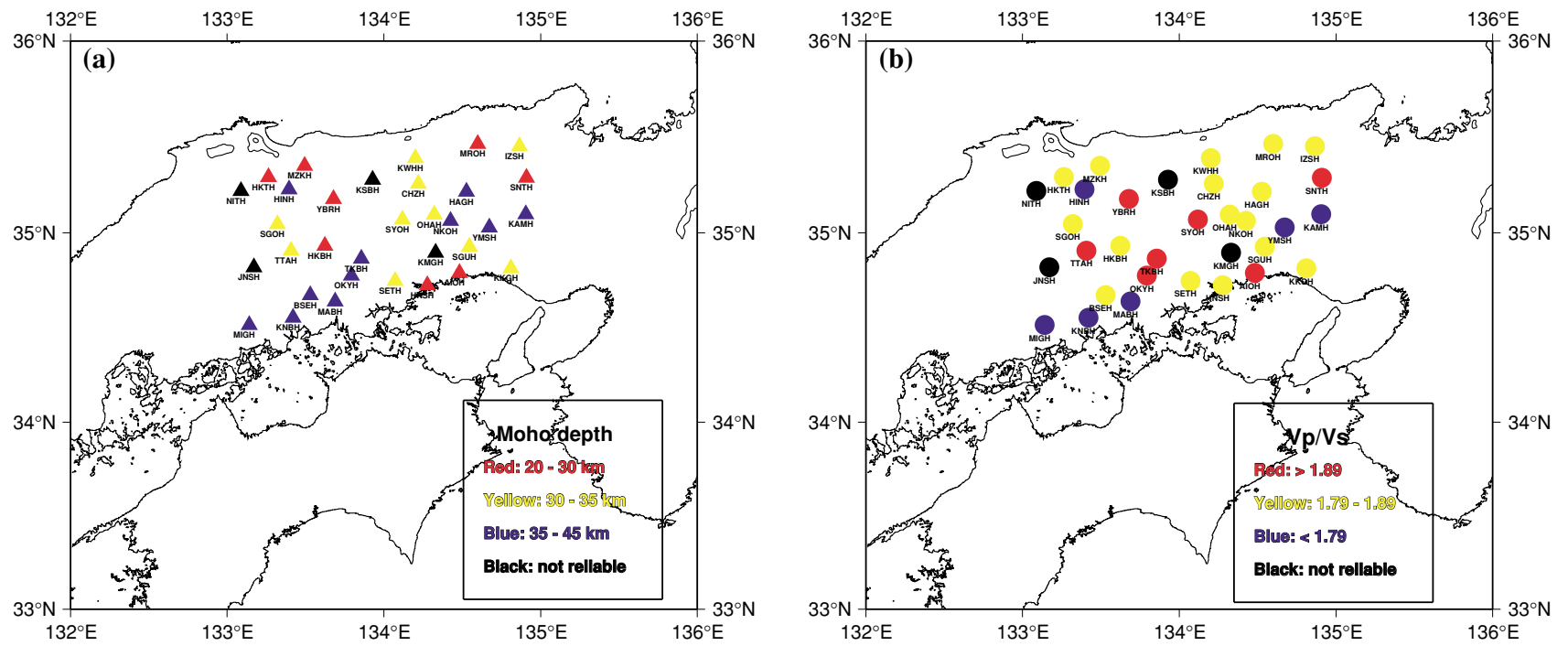

Fig. 6. Colour coded maps of estimates of the crustal parameters $H$ and $V p / V s$. (a) Map shows the colour-coded Moho depth ( $H$ ) estimates at stations. Note the variability in $H$ in the study region with general thinning of the crust in the north and a thicker central region. The colour codes are as mentioned in the inset of the figures. (b) shows the average $V p / V s$ values of the crust broadly divided into three groups; felsic (blue), mafic (yellow) and ultra-mafic (red); recognising 1.79 as a global average. The central high $V p / V s$ values are conspicuous as red.

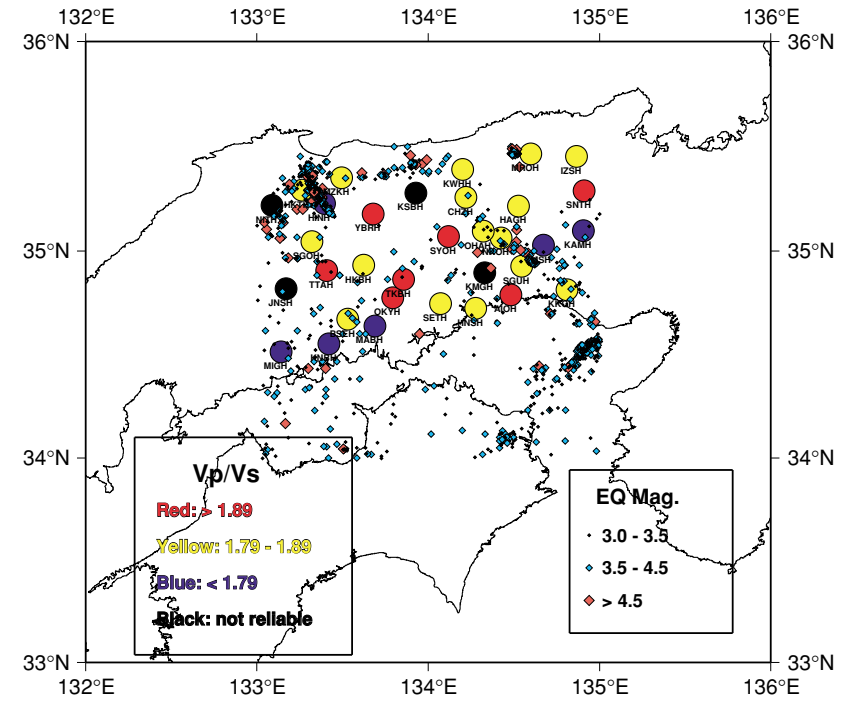

Fig. 7. Correlation of seismicity and $V p / V s$ values. Closed colour circles are $V p / V s$ values at stations. Station names are indicated by four letter codes below each coloured circle. Colour codes and corresponding range of $V p / V s$ values are mentioned in the larger box to the left corner of the figure. Stations where $V p / V s$ measurements are not reliable are represented as black circles. Earthquakes are plotted as diamond symbols. Colour and size of the diamonds indicate their magnitude range. The smaller box in the right corner of the figure shows the magnitude range, their corresponding size and colour.

higher seismicity acting as "stress-barriers". Interestingly, continuous GPS array results show very little deformation in the Chugoku region (Sagiya et al., 2000) that perhaps explains its observed aseismic character. But the apparent correlation between the high Poisson ratio and seismicity remains inexplicable.

\subsection{2-D migrated images}

The tectonic setting of the Japanese islands suggests presence of subducting PHS and PAC plates to the NW and west respectively. The steeply subducting PAC is traced quite reliably till about $600 \mathrm{~km}$ (Zhao et al., 1994) beneath most parts of Japan using broadband data (Tonegawa et al., 2004), while short period results (e.g. Yamauchi et al., 2003) remain silent about it. Interestingly, the northwestward shallow subducting PHS plate that is traced reasonably well in some regions of Japan using above-mentioned short period data, becomes barely visible beneath the study region (Yamauchi et al., 2003; Shiomi et al., 2004). Contrastingly, the broadband images concede that this PHS cannot be seen clearly due to the relatively long period nature of this data (Tonegawa et al., 2004). Therefore, presence of the PHS plate and its disposition in the study region remains ambiguous.

The RFs of restituted data from all the stations were transformed into the depth domain by back-projecting the energy to their corresponding conversion points along their paths, using the IASP91 standard velocity model. This migration is performed by treating all the energy as Ps conversions at discontinuities beneath the stations. To enhance the spatial coherence of the converted phases, these amplitudes corresponding to different depth-offsets are subsequently projected onto a $2 \mathrm{D}$ reference plane. The optimal choice of this plane is based on the subsurface geometry, station disposition and pierce point distribution. The backprojected amplitudes of the RFs falling in a spatial grid are stacked and plotted using a colour scheme where red represents a positive polarity and blue indicates a negative one (e.g. Li et al., 2000; Yuan et al., 2000). In principle, in the same way one could obtain migrated sections using multiple phases (Pps, Pss etc) also to map the Moho, subducting plate etc.

In this study we used a grid size of $2 \times 2 \mathrm{~km}$ in the depth range $0-125 \mathrm{~km}$ to obtain a relatively high-resolution image of the central Chugoku region along NW-SE direction; starting point: $36^{\circ} \mathrm{N}-133^{\circ} \mathrm{E}$ and end point: $34^{\circ} \mathrm{N}-135^{\circ} \mathrm{E}$, i.e. $\mathrm{N} 40^{\circ} \mathrm{W}$; (Fig. 8(a)). We studied the depth domain RFs 

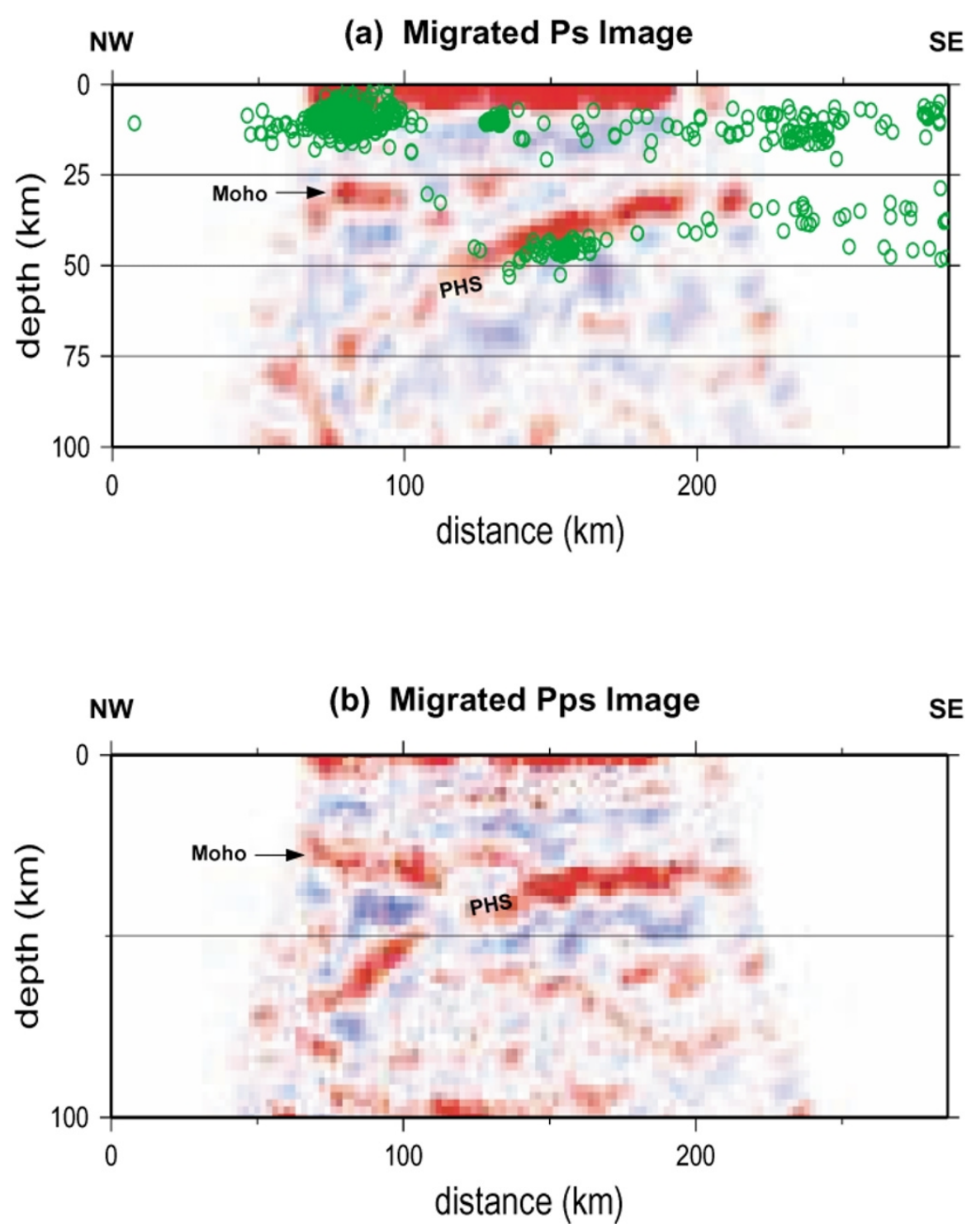

Fig. 8. Ps and Pps migrated images of the PHS. The location of the cross-section (NWSE) for these images is shown by solid line in Fig. 1. In order to enable us to trace the postulated W-NW subducting PHS in southwest Japan, and also capture signatures of the westward dipping PAC in the deeper domains, we obtained 2-D migrated images of the RFs in the study region. To image the shallow dipping PHS we use a finer grid size of $2 \times 2$ km. We obtain two NW-SE sections; one (a) assuming all the later arriving phases to be $P$ - $S$ conversions from depth interfaces and second (b) as $P p s$ multiple ( $P$ multiple of the converted phase). The PHS dipping NW is confirmed by its presence in the $P s$ and $P p s$ images acquiring a steep dip northwestwards reaching depths clearly in excess of $65 \mathrm{~km}$. The seismicity plotted in green also traces the PHS. The Moho in the study region is relatively sharp in the NW and central parts compared to SE.

in the NW-SE cross-section applying various long period filters ( $2 \mathrm{~s}, 3 \mathrm{~s}$ and $5 \mathrm{~s}$ low pass) as well. The robust feature in the migrated sections is the northwest descending PHS with a low dip angle in the southeast part (at depth about $40 \mathrm{~km}$ ) that becomes steeper further northwest reaching depths to about $70 \mathrm{~km}$. Interestingly, the Moho in the northwest part is clear and is around $30-35 \mathrm{~km}$ which is weakly mapped further south and is barely visible in the SE. These features are also indeed reflected in the migrated sections using multiple phases (e.g. Pps, Fig. 8(b)), imparting the desired unambiguity in tracing the PHS that remained largely elusive. Both these features, though reported earlier (e.g. Yamauchi et al., 2003), are more robust and less ambiguous in our migrated images. Earlier, the leading edge of the W-NW subducting PHS is traced at a depth of 50$60 \mathrm{~km}$, sub-parallel to $34.0^{\circ} \mathrm{N}$ close to the Seto inland sea landward (Nakamura et al., 1997).

Using the same procedure, we obtained migrated images of the upper mantle for the depth range $200-800 \mathrm{~km}$ using a grid size of $5 \times 5 \mathrm{~km}$. We applied a $3 \mathrm{~s}$ low pass filter and used a spatial smoothing filter of $5 \mathrm{~km}$ (e.g. Li et al., 2000; Yuan et al., 2000) to enhance correlation in the mantle images (Fig. 9). The main features with some correlation in the migrated sections are presence of a) a band of positive amplitudes with clear horizontal coherence around $300 \mathrm{~km}$, b) a slightly elevated $410-\mathrm{km}$ centered around $400 \mathrm{~km}$, c) strong band of energy closer to $700 \mathrm{~km}$ corresponding to the depressed 660-km discontinuity, showing deepening effect due to subduction d) indications of a westerly subducting PAC starting from $300 \mathrm{~km}$ traceable to about $500 \mathrm{~km}$ as intermittent red patches of energy.

The above observations, an elevated $410-\mathrm{km}$ and a de- 


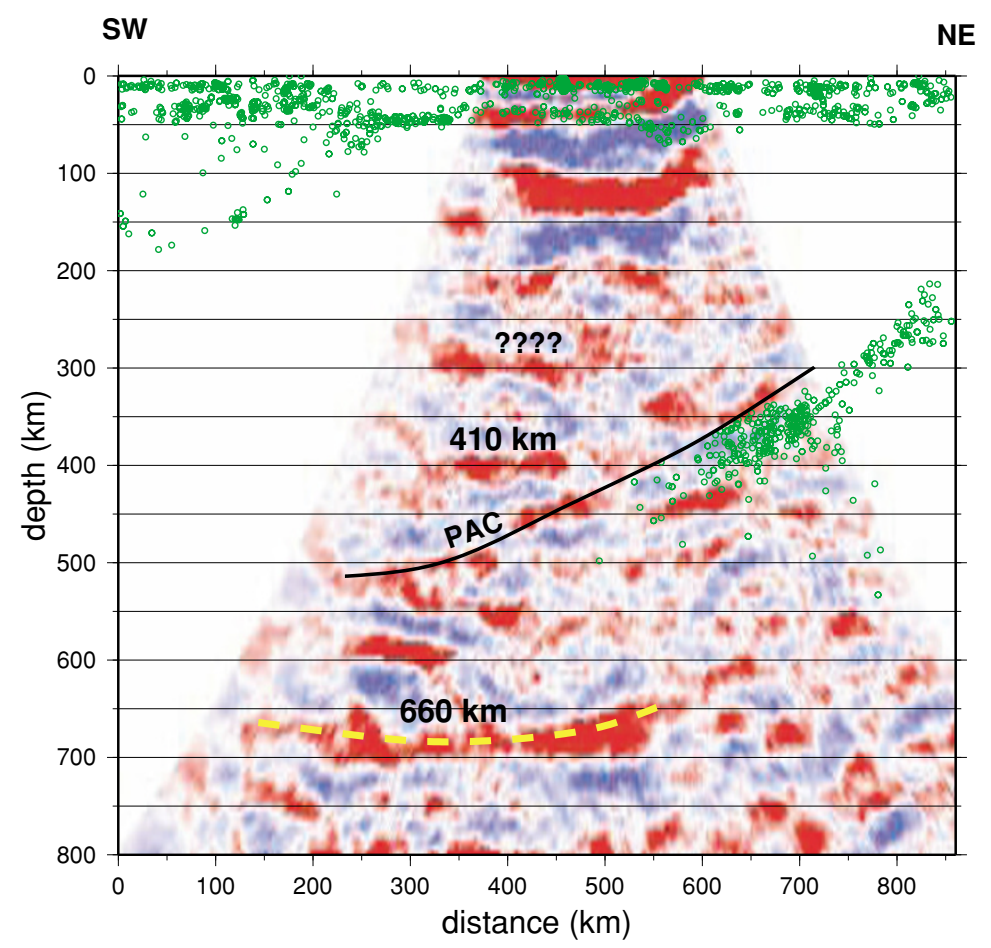

Fig. 9. The mantle image in the cross-section (SW-NE) constructed using a larger grid size of $5 \times 5 \mathrm{~km}$ using RFs that are $3 \mathrm{~s}$ low pass filtered. Location of the cross-section is indicated by dashed line in Fig. 1. The yellow dashed line shows the disposition of the 660-km global discontinuity. The $410-\mathrm{km}$ is marginally elevated by about $20 \mathrm{~km}$ due to the sinking PAC while the 660-km discontinuity is clearly depressed. The global discontinuities show the expected anti-correlation behaviour in a subduction scenario. A clear band of energy well correlated, is around $300 \mathrm{~km}$. A westerly dipping feature showing reasonable correlation but intermittently traceable from $300-500 \mathrm{~km}$, shown by black line, is interpreted as the subducting PAC. The seismicity, between 2000 and March 2004, associated with the PAC and the Japanese crust is also shown in green open symbols. In general, the features mentioned in the mantle are not as robust as those shown in Fig. 8.

pressed $660-\mathrm{km}$, document the deflections in the $410-\mathrm{km}$ and 660-km discontinuities in an anti-correlated fashion on expected lines of Clapeyron slope predictions induced by subduction of the PAC beneath Japanese islands (e.g., Katsura and Ito, 1989; Ito and Takahashi, 1989). Depth contours of the PAC suggest that this westerly subducting plate is expected to be seen between $300 \mathrm{~km}-550 \mathrm{~km}$ in the study region (Zhao et al., 1994). Such a westerly dipping feature corresponding to the subducting PAC is feebly traced from $300 \mathrm{~km}$ to about $550 \mathrm{~km}$ (Fig. 9). It is important to mention that short period RFs yield clear and robust images of the subsurface till $100-150 \mathrm{~km}$ as seen above. On the other hand, the global discontinuities of the upper mantle though mapped remain relatively poorly resolved, as the data is not "broad" enough to capture their signatures more clearly. Presence of the subducting PAC appears suggestive rather than conclusive. One reason could be that the velocity contrast between the PAC and the surrounding mantle at those depths is not sharp and big enough to get reflected in short-period RFs. Another could be that use of limited number of events and stations in this study makes detection of PAC difficult. In general, tracing of slabs beyond 150-200 $\mathrm{km}$ by RFs is seldom possible because of above cited reasons. Interestingly, even broadband data from Japan trace the westward subducting PAC feebly and intermittently till depths as large as $350 \mathrm{~km}$ to about $550 \mathrm{~km}$ beneath the study region. The PAC is weakly mapped in the west compared to its continuous and sharper image till about $200 \mathrm{~km}$ in the northeast Japan (Zhao et al., 1994; Tonegawa et al., 2004).

\section{Conclusions}

In conclusion, a) restituted short period RFs can be used to estimate the crustal thickness $(H)$ and Poisson ratio $(\sigma)$ due to improved quality of the multiple phases (Pps, Pss), b) The Chugoku region has discernible variations in average composition of the crust and its thickness, c) The subducting PHS plate is unambiguously traced beneath Chugoku region reaching depths of about $70 \mathrm{~km}$ using short-period migrated RFs, d) Short-period RFs, in general, do not resolve the deeper domains of the upper mantle with desirable resolution though the global discontinuities can be mapped, e) Presence of the subducting PAC slab at depths 300-550 $\mathrm{km}$ beneath Chugoku region is only suggestive but not conclusive.

Acknowledgments. DSR expresses his deep sense of gratitude to the Director of the Earthquake Research Institute (ERI), University of Tokyo, Tokyo, Japan and to Prof. H. Utada of OHRC, ERI, University of Tokyo, Tokyo, Japan for their kind and warm invitation to visit OHRC, ERI for the 2003-2004 winter semester as a visiting Professor with a generous financial grant. This work would not have been possible without the excellent quality data generated and so willingly shared by all concerned with the Hinet. Indulgence and keen interest of Prof. Fukao in this work is deeply appreciated. The excellent ambience provided by colleagues at OHRC is gratefully acknowledged. Critical reviews by anonymous referees were helpful in revision of the manuscript.

\section{References}

Ito, E. and E. Takahashi, Postspinel transformations in the system $\mathrm{Mg}_{2} \mathrm{SiO}_{4}-\mathrm{Fe}_{2} \mathrm{SiO}_{4}$ and some geophysical implications, J. Geophys. 
Res., 94, 15663-15670, 1989.

Katsura, T. and E. Ito, The system $\mathrm{Mg}_{2} \mathrm{SiO}_{4}-\mathrm{Fe}_{2} \mathrm{SiO}_{4}$ at high pressures and temperatures: Precise determination of stabilities of olivine, modified spinel, and spinel, J. Geophys. Res., 94, 15663-15670, 1989.

Kind, R., G. L. Kosarev, and N. V. Petersen, Receiver functions at the stations of the German Regional Seismic Network (GRSN), Geophys. J. Int., 121, 191-202, 1995.

Li, X., S. V. Sobolev, R. Kind, X. Yuan, and Ch. Estabrook, A detailed receiver function image of the uppermantle discontinuities in the Japan subduction zone, Earth Planet. Sci. Lett., 183, 527-541, 2000.

Nakamura, M., H. Watanabe, T. Konomi, S. Kimura, and K. Miura, Characteristic activities of subcrustal earthquakes along the outer zone of southwestern Japan, Annuals of Disas. Prev. Res. Inst., Kyoto Univ., 40(B-1), 1997 (in Japanese).

Obara, K., Hi-net: High sensitivity seismograph network, Japan, in Methods and Applications of Signal Processing in Seismic Network Operations, edited by T. Takanami and G. Kitagawa, Springer, 266 pp., 79-88, 2002.

Sagiya, T., S. Miyazaki, and T. Tada, Continuous GPS Array and presentday crustal deformation of Japan, Pure and App. Geophysics, 157, 2303-2322, 2000

Shiomi, K., H. Sato, K. Obara, and M. Ohtake, Configuration of subducting Philippine Sea plate beneath southwest Japan revealed from receiver function analysis based on the multivariate autoregressive model, $J$. Geophys. Res., 109, B04308, doi:10.1029/2003JB002774, 2004.

Tada, A., Receiver function imaging of crust and upper mantle discontinuities beneath the Japan Islands, M.Sc. Dissertation thesis of the Depart- ment of Earth and planetary Sciences, Nagoya University, 2001.

Tonegawa, T., K. Hirahara, and T. Shibutani, Detailed structure of the upper mantle discontinuities around the Japan subduction zone imaged by receiver function analyses, Earth Planets Space, 57, 5-14, 2005.

Vinnik, L. P., Detection of waves converted from $P$ to $S V$ in the mantle, Phys. Earth Planet. Int., 15, 294-303, 1977.

Yamauchi, M., K. Hirahara, and T. Shibutani, High resolution receiver function imaging of the seismic velocity discontinuities in the crust and the uppermost mantle beneath southwest Japan, Earth Planets Space, 55, 59-64, 2003.

Yuan, X., J. Ni, R. Kind, J. Mechi, and E. Sandvol, Lithospheric and upper mantle structure of southern Tibet from a passive source experiment, $J$. Geophys. Res., 102, 27,491-27,500, 1997.

Yuan, X. et al., Subduction and collision processes in the central Andes constrained by converted seismic phases, Nature, 408, 958-961, 2000.

Zandt, G. and C. J. Ammon, Continental crust composition constrained by measurements of crustal Poisson's ratio, Nature, 374, 152-154, 1995.

Zhao, D., A. Hasegawa, and H. Kanamori, Deep structure of Japan subduction zone as derived from local and teleseismic events, J. Geophys. Res., 99, 22,313-22,329, 1994.

Zhu, L. and H. Kanamori, Moho depth variation in southern California from teleseismic receiver functions, J. Geophys. Res., 105, 2969-2980, 2000 .

D. S. Ramesh (e-mail: dsramesh@ngri.res.in), H. Kawakatsu (e-mail: hitosi@eri.u-tokyo.ac.jp), S. Watada, and X. Yuan 